\title{
SOCIAL MOVEMENT RHETORIC: A DIALOGUE OF DIFFERENT PERSPECTIVES
}

\author{
Shahreen Mat Nayan \\ University of Malaya, Malaysia
}

\begin{abstract}
The study of social movements in communication has been influenced by both the humanities and the social sciences. Scholars following the functional and/or Burkean perspective offer different lens for understanding movements. However, neither is superior than the other since both perspectives has its own advantages and limitations. This essay seeks to deliberate three main concerns, mainly 1) How have communication scholars treated the rhetoric of social movements? 2) What are the major debates that have shaped the study of Social Movement Rhetoric? and 3) What are the major lapses and/or strengths of social movement rhetoric scholarship, particularly relative to social change outside of the US/West? While this paper is not an exhaustive description of all social-movementsrelated issues, it does however aim to serve as an initial guide for those who wish to understand the nature of social movements from a social science and humanistic lens. Ultimately, this paper also seeks to consider the differing perspectives as a source of dialogue for scholars of social movements.
\end{abstract}

Keywords: Social movements, Communication, Rhetoric, Social change

\section{Introduction}

The topic of social movements has been studied for decades. Yet, there remain disputes with regards to what exactly makes up a social 
movement (Stewart, Smith \& Denton, 2007). Stewart et al. (2007) in Persuasion and Social Movements highlights the main characteristics of social movements while discussing how social movements is distinct from other groups such as political parties, institutions etc. In this paper, I first define social movements, before I discuss the ways in which communication scholars have treated the rhetoric of social movements. In the second part, I summarize some of the major debates that have shaped the study of social movement rhetoric. Finally, I call attention to the major lapses and/or strengths of social movement rhetoric scholarship, particularly relative to social change outside of the United States or the West in general. It is hoped that by doing this, our understanding of social movements will be more inclusive, and not limited to views which tend to be Western-centric. Additionally, by highlighting the multiple perspectives, this paper does not aspire to prove whether there is one view that is leading compared to the rest. Rather, what this paper hopes to commence is a dialogue and understanding of the various ways of studying social movements.

\section{Defining Social Movements}

Defining social movements can be a challenge since scholars in the social sciences tend to view it differently than scholars in the humanities. Deluca (1999) in Image Politics turned to Webster's Encyclopedic Unabridged Dictionary to underline three definitions of movement: "A progressive development of ideas toward a particular conclusions; $A$ series of actions or activities directed or tending toward a particular end; And, a diffusely organized or heterogeneous group of people or organizations tending toward or favouring a generalized common goal" (p.28) [emphasis by author].

Compared to the third definition given, the first two are seen as more compatible with rhetorical studies. This is particularly true if one were to view social movements from a humanistic perspective. In Cox and Foust (2009), for instance, two perspectives concerning social movements were outlined. The first perspective highlighted social movements as something that includes a leader-centred approach inspired by new sociological theories (identifying core functions of movements). The scholars' second perspective, considered more Burkean in approach, viewed movements as dramatistic forms. Between the two standpoints provided by Cox and Foust (2009), the latter may be seen as 
more humanistic in perspective. I elaborate more on what is meant by drama in the next section.

\section{Characteristics}

For Stewart, Smith and Denton (2007), a social movement must be at least minimally structured or organized. The scholars are of the opinion that, if we cannot single out a leader or spokespersons, members/followers and partnerships, then the events under investigation is merely a trend or a riot, or even a spontaneous protest. Thus, it cannot be considered a social movement.

Stewart, Smith and Denton (2007) remind those interested in the study of social movements of the distinction between such movement groups from the other types such as political parties or institutions. They claim that there are two main differences. The first difference between social movements and other types lies in the fact that social movements are mostly organized outside of more established organizations. More importantly, social movements consist of primarily ordinary people. For instance, these groups do not require their leader(s) to be from any distinguished organizations, nor do the leaders have to be a prominent figure. As a matter of fact, "they cease to be social movements if they become parts of institutions" (Stewart, Smith \& Denton, 2007, p.7). Other characteristics of social movements listed by Stewart et al. (2007) are summarized as follow:

1. Social movements are "out-groups". They are often viewed as unlawful, and therefore denounced for using communication channels that are considered unconventional. Social movements are often marginalized by mainstream media outlets and work with very little (if any) funds. This basically leaves them with persuasion or rhetoric as their primary tool to move forward.

2. Large in scope - social movements are not limited to a large number of memberships. Rather, social movements are also considered large in terms of the geographical area covered and the length of time spent on pursuing and advocating their cause. These elements make social movements distinct from other types of pressure groups.

3. Promotes or oppose change in societal norms - Not only do social movements challenge social norms, they also go 
further by suggesting what needs to be done, by whom, and in what manner must the actions be executed.

4. Encounters opposition in moral struggle - Social movements are said to believe they have a moral responsibility to make known to others the corrupt ways or weaknesses of the targeted institutions.

5. Persuasion is pervasive - To meet their goals, social movements may use coercion, bargaining and persuasion. However, due to limitations or constraints in terms of their capability and/or resources, persuasion is the main method chosen by most social movements to meet their objectives. Their rhetorical strategies can be either verbal or non-verbal as well as employ aids such as images, speeches, and even an activist's own body (Stewart, Smith \& Denton, 2007, p. 8-19).

In sum, from the perspective of Stewart et al. (2007), a social movement is "an organized, uninstitutionalized, and large collectivity that emerges to promote or resist change in societal norms and values, operating primarily through persuasion encountering opposition (in its moral struggle)" (p. 24). The following section highlights some of the ways in which scholars in communication have viewed the rhetoric of social movements.

\section{How have communication scholars treated the rhetoric of social movements?}

Scholars who study social movements have a tendency to analyse it from an organizational perspective, even though a rhetorical perspective also offers many distinctive benefits (DeLuca, 1999). As previously mentioned, the two perspectives in the study of social movements are 1) leader-centred or the "functional" approach, and 2) A Burkean or "dramatistic" approach (Cox \& Foust, 2009).

The functional approach basically treats social movements as uninstitutionalized organizations. Stewart (in Cox and Foust, 2009) asserts that this approach leans more towards the social sciences where theories aim to generalize or categorize social movements. The functional approach help identify challenges and tactics of social movements. On the other hand, it provides a limited view of what "change" is. Echoing Stewart, Cox and Foust (2009) maintained that 
although the functional approach is a useful means to study the rhetoric of social movements, it tended to remove the centrality of specific events, speeches and even strategies. In contrast to the functional approach, the dialectical form is influenced by Kenneth Burke and offers a broader scope for the study of movements and change. Griffin (1969) offers a comprehensive explanation of the Burkean perspective. At its most fundamental level, "man" for Burke (in Griffin, 1969) is considered,

[t]he symbol-using (symbol-making, symbol misusing) animal inventor of the negative (or moralized by the negative) separated from his natural condition by instruments of his own making goaded by the spirit of hierarchy (or moved by the sense of order) and rotten with perfection (p. 457).

Put differently, Man from a Burkean perspective is "divided" and "designed for striving," he is also an "actor, a maker, a mover; a being who lives by striving". Since man is divided, what is considered right or good for one individual, may be considered the opposite for another. Furthermore, since man is ambitious and "ambition is a disease that ends in pride" (Griffin, p. 460), there will always be a tendency for symbols to be misused. In some ways, Burke's dramatistic views are similar to Shakespeare's view of the world as a stage and humans as actors. Hence, for Griffin, to study a social movement is akin to studying a drama, or an act of transformation.

Further in the discourse surrounding the rhetoric of social movements, McGee (2006) also offers an intriguing standpoint. For McGee, a movement "is a set of meaning and not a phenomenon" (2006, p.115). McGee believes that the study of social movements is more relevant to the study of human consciousness. Burke or McGee's perspective allows students of rhetoric a lens that is wider for interpretation. While the functional approach may be pragmatic for sense-making, we may risk overlooking the finer details that make up a movement. DeLuca (1999) mentions the significance of "making the invisible matter" (p. 31) and reminds us that theories can be both frames for seeing as well as blinders. If movements were pigeon-holed into categories resembling organizations, movements (especially those considered more radical in nature) may not be counted or may even be seen as "non-existent" (DeLuca, 1999, p. 32). 
Referencing McGee's definition of social movement as consciousness, we may refer to the tiny-house movement as an interesting example ${ }^{1}$. The tiny-house movement illustrates a state of consciousness that privileges liberation from consumer culture. It does not concern itself with rebelling against some higher figure or institution. Rather, it goes deeper by ignoring mainstream discourse that often pays too much attention to consumer culture and the material world.

\section{Major debates that shape the study of Social Movement Rhetoric}

This section puts forward some of the major debates in the study of social movement rhetoric. The topics are not meant to be exhaustive. It is merely a humble attempt to provide an overview of some of the debates that surround the rhetoric of social movements. Apart from deliberation on what constitutes social movement, persuasion and coercion seem to be two main topics of debate in the study of social movement rhetoric.

There seems to be a fine line between the two. In the case of body rhetoric for example, scholars disagree whether it counts as a form of persuasion or coercion. Stewart, Smith and Denton (2007), quotes Turner and Killian when they defined coercion as the "manipulation of the target group's situation in such fashion that the pursuit of any course of action other than that sought by the movement will be met with considerable cost or punishment" (p.20). Simply put, coercion results in some form of loss for the target group, if a particular movement's demands are not resolved. Interestingly, for Garsten (2004), "To truly persuade people is to induce them to change their own beliefs and desires in light of what has been said... the difference between being persuaded and being indoctrinated or brainwashed... lies in the active independence that is preserved when we are persuaded" (p.7).

In Cox and Foust (2009), Andrews argued that the rhetoric of Students for Democratic Society was coercive because it restricted the audience's choice. At the same time however some scholars contend that if we were to ignore the legitimacy of body rhetoric or continue to maintain it as coercive, we risk maintaining an unfair status quo (Cox \& Foust, 2009). Not everyone has the means to rational communication. Therefore, there are times when body rhetoric becomes a necessity.

So when is body rhetoric considered coercion? Body rhetoric becomes coercive when the system feels forced to fulfil the demands of the movement/protestors. This is especially true if the manner in which the protest is conducted becomes an inconvenience to a society. Haiman 
(2006) spoke of this when he discussed the rhetoric of the streets. While protestors may gain by getting much of the needed attention, protestors may inconvenience others, for instance, tax payers and "innocent bystanders" by interrupting the people's daily lives or productivity.

Additionally, issues of ethics arise when one questions the necessity of civil obedience in a society that provides appropriate or legal channels. "One cannot condone civil disobedience for the 'good guys' without allowing it for the 'bad guys' . . Justice must be impartial and even-handed" (Haiman, 2006, p. 15). However, if the stage is always made available for the "good" and "bad" guys, what kind of chaos would occur? Is it worth allowing a small group of protestors to take the stage or should all types of protest be silenced for the sake of peace? Griffin (in Haiman, 2006) believes that body rhetoric is not considered persuasion because it is akin to "holding of a gun to the head" (p. 17). When then, does body rhetoric ${ }^{2}$ become persuasive? How do individuals in oppressed societies voice their discontent when the system does not support appropriate channels to vent their frustrations? ${ }^{3}$

An important fact to note is many among those involved in civil disobedience seek no exemption from punishment, that is, jail time (Haiman, 2006) and contends that " $[\mathrm{t}]$ hey are keenly aware that a lawless society cannot survive, but they are willing to pay whatever penalties the civil law may exact in order to obey what they regard as a higher law..." (p.17). Some would argue that by sacrificing their freedom, protestors actually gain by elevating their cause and gaining more attention. So, will a person's willingness to suffer consequences make movements more persuasive and less coercive? If we return to Garsten's (2006) definition, it is not necessarily so. Since persuasion needs to include consent or willingness (Garsten, 2006) and free choice (Andrews, 2006). Therefore, one may argue that, although powerful in presence, body alone is not enough.

Butterworth (2008) goes one step further by reminding rhetorical critics to be careful not to overestimate the body's ability to argue or resist. He speaks of Katie Hnida as a prime example. In his example, Katie Hnida's ${ }^{4}$ rhetoric did not result in a positive outcome. Although the body shows that there is "a material dimension to rhetoric" (Selzer in Butterworth, 2008, p. 261), it can also sometimes be a distraction and lead to a situation or discourse not meant to be part of the speaker's intent (Butterworth, 2008). Based on this perspective, one may conclude that body rhetoric alone and without rational speech to persuade may not 
necessarily be the ideal catalyst for change. This leads to the next topic concerning change - is confrontation necessary for change to take place?

According to Scott and Smith (1969) confrontation was "the guarantee of open communication and fruitful dissent" (p. 1). For them, confrontation was a viable tactic to open up space for negotiation or communication. When discussing strategies for movements, Simons (1970) looks at militant versus moderate, or what he refers to as revolutionary and reformist movements. Moderates basically correlate with "the pattern of peaceful persuasion rhetoricians knows best and characteristically prescribe the embodiment of reason, civility, and decorum in human interaction..." (p. 7). On the other hand, militants seek for change via "means of direct action techniques and verbal polimecs, miltitants threaten, harass, cajole, disrupt, provoke, intimidate, coerce" (p. 8). Militants are also more likely to utilize body rhetoric to add drama to their cause. Although militant tactics gain greater visibility, it is usually the moderates who are included in the process of deliberation. Ideally, movements need to balance the two approaches to gain access to those in public positions while at the same time remain relevant to the movement's followers. However, by being "radical conservative" (Simons, 1970), the movement may risk positioning itself inconsistent, unstable and irrelevant to all parties.

Simons (1970) mentioned Martin Luther King as an example of a movement leader who managed to balance the reform and radical approach. In this sense, one may conclude that Simon's analysis is in line with Scott and Smith (1969) who view confrontation as a necessity for movements. Following these perspectives, Cathcart (2006) goes further by claiming that confrontation is not limited to opening up channels of communication. Instead, confrontation may be viewed as a prerequisite for a movement for the process of identification. For Cathcart (2006, p. 100 ), confrontation is not about notions of violence but rather it concerns symbolic displays or "dramatistic form" that may or may not include acts of direct action or such things as body rhetoric. Cathcart is of the opinion that it is confrontation that makes a movement's rhetoric distinct from the masses. Cathcart emphasizes the fact that it is confrontation that "gives a movement its identity, its substance and form. No movement for radical change can be taken seriously without acts of confrontation" ( $p$. 100). For Cathcart, confrontation is not just about collective agency but also makes a movement more meaningful - making its cause clear. For without confrontation, "a movement would not be able to identify its true believers" (p. 102). So, does this mean confrontation is an absolute must 
for movements? If we look at the workings of James Scott (1990), it may not necessarily mean so.

In his analysis, Scott (1990) maintained that in some instances, the subordinate class may appear to be cooperating with the dominant, even though in reality they are resisting in "safe" and subtle ways. The resistance displayed by the village folk (a Malay village to be precise) in Scott's study may not be organized, but it was clearly forms of protest. Scott referred to their act of resistance as "hidden transcripts". That is, discourse that happens when the dominant is not present. Examples of hidden transcripts include gossip and sabotage.

Acts of resistance from certain groups, such as those who are less privileged or those in the minority/marginalized population are sometimes kept hidden for fear of punishment or some other negative consequences. Scott's (1990) discussion of resistance may not be commonly studied in Western scholarship on social movements. And although this type of movement (one that lacks confrontation) may not be considered radical, or even functional for some, it may be the only way some movements can operate. Whether social movement scholars would agree that Scott's case study would constitute a movement, we have yet to discover. This leads me to the third topic of debate among scholars the discourse on counterpublics.

According to Cox and Foust (2009), the term counterpublic is inconsistently defined by scholars. "In some cases, the term appears to be simply for 'movement' or as a synonym for 'new social movements,' while in other cases, 'counterpublic' signals the internal, reflexive discourse of a group's turn away from dominant publics to focus inward" (Cox \& Foust, 2009, p. 612). In reference to Brouwer (2006), counterpublics appear when certain individuals feel sidelined from the dominant group. Brouwer contends, not all important speech is made public. However, just because a movement is not made public, it may still maintain its tactics and significance. From this, we may assume that since movements are not immune from distancing its own members ${ }^{5}$, counterpublics can exist within a movement. Peasant resistance as discussed by Scott (1990) may perhaps be an example of what constitutes a counterpublic. For Brouwer, one of the challenges in studying the concept of counterpublics is the Western concept used to identify or speak of the state and the marginalized population. This leads to the final section of my paper relating to non-Western rhetoric. 


\section{Major lapses and/or strengths of Social Movement Rhetoric scholarship}

The functional and dialectic approach in the study of social movements enables scholars the opportunity to analyse the phenomenon in multiple ways. Research on social movement rhetoric is no longer just leadercentred. Multiple perspectives make it less likely that a given movement is overlooked. Despite this strength however the area of social movement rhetoric outside of the West is still lacking. In the Western context, one may see some non-Western influence via Ghandi's nonviolent rhetoric in Martin Luther King's speech or tactic. Yet, despite its influence, scholars have not focused on non-Western forms of rhetoric. Furthermore, in the study of social movements, "Rhetorical scholars have heretofore confined themselves almost exclusively to investigating movements indigenous to America or Great Britain. Yet the social, political, and religious values and institutions, as well as the rhetorical traditions and praxes, of Anglo-America are not necessarily those of other Western nations and are most certainly not those of non-Occidental nations" (Lucas, 2006, p. 142). Lucas contends, as rhetorical scholars, we should make an effort to understand the rhetoric of non-Western movements. Unless we do so, our understanding will remain partial. Culture and diversity in opinion are important ingredients that should not be overlooked by rhetoricians. Kirkscey (2007) believes rhetorical critics should diversify their knowledge. Kirkscey's stance is in line with Lucas. $\mathrm{He}$ is of the opinion that, "rhetorical critics should increase their investigation of social movements through research in fields such as anthropology, fol klore and linguistics. In light of recent political, gender, and economic power transitions... artifacts will continue to appear from emerging rhetors whose voices have been oppressed in the past..." (p. 16).

The need for more studies on non-Western rhetoric and movements is recognized, yet why is it still lacking? Perhaps, one main reason is because no one is quite sure about the similarities and/or distinction between the West and non-Western rhetoric. Non-Western form of rhetoric is certainly not a novel idea. George A. Kennedy's (1998) Comparative Rhetoric is dedicated to the study of rhetoric from a cross-cultural perspective. Kennedy specifically evaluates traditional Western rhetorical concepts in comparison to non-Western rhetoric. He describes comparative rhetoric as "the cross-cultural study of rhetorical traditions as they exist or have existed in different societies around the 
world" (p. 1). Comparative rhetoric, according to Kennedy has, at the very least, four objectives:

1. To identify what is universal and what is distinctive about any one rhetorical tradition in comparison to others.

2. To formulate a general theory of rhetoric that will apply in all societies.

3. To develop and test structures and terminology that can be used to describe rhetorical practices cross-culturally.

4. To apply what has been learned from comparative study to contemporary cross-cultural communication.

(Kennedy, 1998, p.1)

According to Kennedy, one of the challenges faced by those interested in comparative rhetoric is the language and culture barrier. $\mathrm{He}$ claims that neither he nor anyone else he knows is competent to give an authoritative account of the rhetorical practices of the many different cultures. This is mostly because no one has mastered the wide area of knowledge of the many languages and societies of the world. Kennedy (1998) insists,

I draw on a large body of research by linguists, anthropologists, social biologists, and experts in nonWestern societies, most of whom never use the word "rhetoric," though to me that is often what they seem to be discussing (p. 2).

Although not all cultures may use the term rhetoric, almost all have views on its significance. For instance, Esack (2002) spoke of the significance of the oral tradition in Arab cultural life. According to Esack, in the Arab culture, one's eloquence was symbolic of his/her wisdom. Esack also mentions that Arab lexicographers explain how the word "Arab" means "eloquent expression" or "effective oral communication". He claims non-Arabs were referred to as "al-'ajam", meaning "those who cannot express themselves eloquently" (p. 35).

Wang's (2004) survey of research in Asian rhetoric offers an insightful overview of the current scholarship on non-Western rhetoric. In Wang's study, different voices (Vernon Jensen, Mary Garrett, Xing $\mathrm{Lu}$, and LuMing Mao) offer deep reflections on the issue of non-Western rhetoric. Wang notes how important research in Asian rhetoric is wary of 
Orientalism, while taking into account cultural and political contexts. It is stressed that,

Researchers in Asian rhetoric must challenge the fundamental assumptions about rhetoric embedded in classical Western rhetorical theories to start a conversation between East and West... we need to be cautious not to impose the Western conception of rhetoric upon the description of Asian rhetorics... relying too heavily on classical Western rhetorical theory without transforming it from the perspectives on nonWestern rhetorical traditions might perpetuate the idea that Greco-Roman rhetorical tradition is the only rhetorical tradition.

Basically, Wang's survey illustrate the importance of analysing non-Western rhetoric on its own terms - highlighting its distinct features while at the same time not ignoring similarities (if any) that exist with the West.

Besides the language and cultural factor, XiaoMing Li (in Wang, 2004) feels that the enthusiasm to do postmodern theory in the last decade may be one of the reasons why cultures perceived as less advanced tend to be overlooked. This is especially true when some of these cultures have a tendency to write in plain manner, instead of more fancy or ambiguous language. Due to this reasoning, "New theories with a French accent therefore, are adopted with great gusto, while nonWestern rhetoric is accepted with polite tolerance" (XiaoMing Li in Wang, 2004, p. 177). For those who feel the lack of interest in studying rhetoric outside of the West, Kennedy (1998) reminds us that there are some clear distinctions that may be worth looking into. Western rhetoric, according to Kennedy is considered more "tolerant of contention, personal invective, and flattery" (p. 217). On the other side, more emphasis is placed on consensus, politeness and restraint.

Besides the dearth of scholarship on non-Western rhetoric, a second area that is still lacking is studies on nonviolent or peaceful persuasion. Nonviolent rhetoric basically signify a form of communication that is void of hostility. Great leaders such as Mahatma Ghandi and Martin Luther King Jr. have been known to use this form of rhetoric. Despite the rhetorical value in this form of address, rhetorical 
theorists have yet to play closer attention to nonviolence as a rhetorical form (Gorsevksi, 2004). Here, I am not implying that there is a complete absence of scholarship on nonviolent rhetoric. Gorsevski (2004) and Palmer-Mehta (2009) offer some useful examples of work relating to nonviolence. I am simply highlighting here, there is room for improvement.

Gorsevski believes that nonviolent rhetoric is understudied mainly because using peaceful means to address conflict is often seen as a sign of weakness, naivety and idealistic. In reality, there is more to nonviolent rhetoric than meets the eye. Culture may possibly play a role in this since some cultures place more emphasis on uniformity, and discourages confrontation. Kennedy (1998) highlights this when we reported how uniformity is still highly valued in many non-Western nations. He states, "Deliberation in traditional societies achieves apparent unanimity by politeness, restraint, and the use of formal language. A speaker may offer a suggestion and indicate willingness to withdraw it or compromise. Criticism is made indirectly. . Emotion is controlled. Opponents allow each other to 'save face.' Silence is taken to mean agreement" (p. 221). One question comes to mind - since some cultures place more value on restraint, uniformity and silence, would notions of nonviolence be more relevant to study such communities?

In relation to nonviolent rhetoric, Sharp (1996) reminds us that people power and nonviolent action can be just as powerful in comparison to violent means, since the power of a government lies in the people. The dominant loses its power if/when the people refuse to obey. In agreement with Sharp and Gorsevski, the topic of nonviolence is worthy of further analysis.

\section{Conclusion}

The study of social movements in communication has been influenced by both the humanities and the social sciences. Scholars following the functional and/or Burkean perspective basically offer different lens of "reading" movements. Neither is superior than the other since both perspectives has its own advantages and limitations. Also, one approach is not necessarily more accurate than the other. For instance, though one may be more social science in approach and is considered more "limiting", it may prove to be a good starting point or even guideline for reasons related to pedagogy (for example, more practical or accessible for the novice scholar), before moving on to the Burkean approach. 
Movement scholars need to be well versed with both perspectives, although they may have a preference for utilizing only one lens. In reference to comparative rhetoric, more can be done than just comparing the similarities and distinction between Western and non-Western rhetoric. The fact remains, context and culture cannot be simplistically categorized. All these, are legitimate reasons for dialogue and understanding.

\section{Endnote}

${ }^{1}$ For a general overview on this phenomenon, an Internet search on "the tiny house movement" or "Jay Shafer + tiny house movement" may be useful.

${ }^{2}$ An example of a social movement that incorporates body rhetoric would be the Chipko in India.

${ }^{3}$ I am left wondering whether online or digital protest would be the answer for those who live in societies where free speech is not made available. But, would this simply provide a false sense of free speech?

${ }^{4}$ Hnida was the first woman to play division 1 college football.

${ }^{5}$ An example of this would be Paul Watson's break from Greenpeace to form Sea Shepherd

\section{References}

Andrews, J. R. (2006). Confrontation at Columbia: A case study in coercive rhetoric. In Morris \& Browne (Eds.), Readings on the Rhetoric of Social Protest (2nd ed.) (pp. 165-171). Pennsylvania: Strata Publishing, Inc.

Brouwer, D. C. (2006). Communication as counterpublic. In G. J. Shepherd, J. St. John, \& T. Striphas (Eds.), Communication as .... Perspectives on theory (pp. 195-208). Thousand Oaks, CA: Sage.

Butterworth, M. L. (2008). "Katie was not only a girl, she was terrible": Katie Hnida, body rhetoric, and football at the University of Colorado. Communication Studies, 59(3), 259-273.

Cathcart, R. S. (2006). Movements: Confrontation as rhetorical form. In Morris \& Browne (Eds.), Readings on the Rhetoric of Social 
Protest (2nd ed.) (pp. 95-103). Pennsylvania: Strata Publishing, Inc.

Cox, R. \& Foust, C. R. (2009). Social movement rhetoric. In A. Lunsford, K. H. Wilson, \& R. A. Eberly (Eds.), The SAGE Handbook of Rhetorical Studies (pp. 605-627). Thousand Oaks, CA: Sage.

DeLuca, K. M. (1999). Image politics: The new rhetoric of environmental activism. New York: The Guilford Press.

Esack, F. (2002). The Qur'an: A short introduction. Oxford, England: Oneworld Publications.

Garsten, B. (2006). Saving persuasion: A defense of rhetoric and judgment. Cambridge, Massachusetts: Harvard University Press.

Gorsevski, E. W. (2004). Peaceful persuasion: The geopolitics of nonviolent rhetoric. Albany: State University of New York Press.

Griffin, L.M. (1969). A dramatistic theory of the Rhetoric of movements. In W.H. Rueckert (Ed.), Critical responses to Kenneth Burke, 1922-1966 (pp. 456-478). Minneapolis: University of Minnesota Press.

Haiman, F. S. (2006). The rhetoric of the streets: Some legal and ethical considerations. In Morris \& Browne (Eds.), Readings on the Rhetoric of Social Protest (2nd ed.) (pp. 14-28). Pennsylvania: Strata Publishing, Inc.

Kennedy, G. A. (1998). Comparative rhetoric: An historical and crosscultural introduction. New York: Oxford University Press.

Kirkscey, R. (2007). Accommodating traditional African values and globalization: Narrative as argument in Wangari Maathai's Nobel Prize lecture. Women and Language, 30(2), 12-17.

Lucas, S. E. (2006). Coming to terms with movement studies. In Morris \& Browne (Eds.), Readings on the Rhetoric of Social Protest (2nd ed.) (pp. 134-145). Pennsylvania: Strata Publishing, Inc.

McGee, M. C. (2006). "Social movement": Phenomenon or meaning? In Morris \& Browne (Eds.), Readings on the Rhetoric of Social Protest (2nd ed.) (pp. 115-126). Pennsylvania: Strata Publishing, Inc.

Palmer-Mehta, V. (2009). Aung San Suu Kyi and the Rhetoric of Social Protest in Burma. Women's Study in Communication, 32(2), 151179.

Scott, J. C. (1990). Domination and the arts of resistance: Hidden transcripts. New Haven: Yale University Press. 
Scott, R. L. \& Smith, D. K. (1969). The rhetoric of confrontation. The Quarterly Journal of Speech, LV(1), 1-8.

Sharp, G. (1996). Beyond just war and pacifism. Ecumenical Review, 48(2), 233-250.

Simons, H. W. (1970). Requirements, problems, and strategies: A theory of persuasion for social movements. The Quarterly Journal of Speech, LVI(1), 11.

Stewart, C. J., Smith, C. A., \& Denton, R. E. (2007). Persuasion and social movements. Waveland Press, Inc.: Long Grove, Illinois.

Wang, B. (2004). A survey of research in Asian rhetoric. Rhetoric F 